OPEN ACCESS

Edited by:

Dimpna Calila Albert-Brotons, King Faisal Specialist Hospital \& Research Centre, Saudi Arabia

Reviewed by: Giovanni Di Salvo

University of Padua, Italy Adam James,

Our Lady's Children's Hospital (CHI), Ireland

Claire Dauphin

Centre Hospitalier Universitaire de Clermont-Ferrand, France

Thomas Krasemann,

Sophia Children's

Hospital, Netherlands

*Correspondence:

Marien Lenoir

marien.lenoir@ap-hm.fr

tThese authors have contributed equally to this work

Specialty section

This article was submitted to Pediatric Cardiology

a section of the journal

Frontiers in Pediatrics

Received: 25 April 2021 Accepted: 12 October 2021 Published: 19 November 2021

Citation:

Lenoir $M$, Wanert $C$, Bonnet $D$,

Méot M, Tosello B, Fouilloux V, Ovaert $C$ and Malekzadeh-Milani S (2021) Anterior Minithoracotomy vs.

Transcatheter Closure of Patent Ductus Arteriosus in Very Preterm Infants. Front. Pediatr. 9:700284. doi: 10.3389/fped.2021.700284

\section{Anterior Minithoracotomy vs. Transcatheter Closure of Patent Ductus Arteriosus in Very Preterm Infants}

\author{
Marien Lenoir ${ }^{1 * \dagger}$, Chloé Wanert ${ }^{2 \dagger}$, Damien Bonnet ${ }^{3,4}$, Mathilde Méot $^{3}$, \\ Barthélémy Tosello ${ }^{5,6}$, Virginie Fouilloux ${ }^{1}$, Caroline Ovaert ${ }^{2,6 t}$ and \\ Sophie Malekzadeh-Milani ${ }^{3+}$
}

${ }^{1}$ Department of Pediatric Cardiac Surgery, Hôpital Timone Enfant, AP-HM, Marseille, France, ${ }^{2}$ Department of Pediatric Cardiology, Hôpital Timone Enfant, AP-HM, Marseille, France, ${ }^{3} \mathrm{M} 3 \mathrm{C}-\mathrm{N}$ - cker, Hôpital Universitaire Necker-Enfants Malades, AP-HP, Paris, France, ${ }^{4}$ University of Paris, Paris, France, ${ }^{5}$ Department of Neonatology, Hôpital Nord, AP-HM, Marseille, France, ${ }^{6}$ Aix-Marseille University, MMG, INSERM, Marseille, France

Introduction: Patent ductus arteriosus (PDA) is common in preterm infants and contributes to morbidity and mortality. Several studies have shown the feasibility and safety of percutaneous PDA closure. Minimally invasive surgical ligation by anterior thoracotomy is an alternative, bedside technique for PDA closure in very low birth weight preterm infants. Our study aimed to compare short- and medium-term morbidity and mortality between anterior minithoracotomy and transcatheter PDA closure.

Methods: From 2010 to 2020, 92 preterm infants $<1,600 \mathrm{~g}$ underwent PDA closure in two centers: 44 surgical anterior minithoracotomies (center 1) and 48 transcatheter closures (center 2). Using a 1:1 propensity score match analysis, 22 patients in each group were included. The primary outcome was time to extubation after intervention.

Results: Preoperative characteristics were similar in both groups after propensity matching (mean weight at procedure, $1,171 \pm 183 \mathrm{~g} ; p=0.8$ ). Mean time to extubation was similar: $10 \pm 15$ days in the surgical group vs. $9 \pm 13$ days in the transcatheter group $(p=0.9)$. Mean age at hospital discharge was $114 \pm 29$ days vs. $105 \pm 19$ days $(p=0.2)$. Two deaths occurred in the surgical group and one in the transcatheter group ( $p=0.61$ ). Five complications (pneumothorax $n=2$, chylothorax $n=2$, phrenic nerve injury $n=1$ ) occurred in three patients after surgery. Three complications (chylothorax $n=1$, endocarditis $n=1$, renal vein thrombosis $n=1$ ) occurred in two patients after percutaneous closure $(p=0.63)$.

Conclusion: Equivalent efficiency and safety of surgical mini-invasive vs. transcatheter PDA closure in preterm infants $<1,600 \mathrm{~g}$ are in favor of applying these alternative techniques according to centers' facilities and competences.

Keywords: transcatheter closure, mini-invasive surgery, prematurity, patent ductus arteriosus, very low birth weight preterm infant 


\section{INTRODUCTION}

Patent ductus arteriosus (PDA) is very common in preterm newborns and is inversely related to gestational age (weeks) (1). The incidence ranges from 60 to $80 \%$ for preterm infants born between 25 and 28 weeks and up to $90 \%$ for those born at 24 weeks $(1,2)$. PDA can result in a significant left-to-right shunting and has been associated with neonatal morbidities: bronchopulmonary dysplasia (BPD), intraventricular hemorrhage (IVH), acute renal failure, necrotizing enterocolitis (NEC), and retinopathy of prematurity (ROP) (1, 3-7). The management of PDA remains controversial. Various treatment options and algorithms are available, but no robust recommendations exist $(1,6)$. Medical therapy [mostly non-steroidal anti-inflammatory drugs (NSAIDs)] is usually the first-line option, with interventional closure reserved to medical treatment failure or contraindication (7). The current trend is a decrease in surgical treatment.

Surgical PDA ligation was initially described by Gross and consisted in a left thoracotomy with ligation and division of the PDA (8). This technique remains the most frequently performed. In very low weight preterm (VLWB) infants, surgical ligation can be performed through anterior minithoracotomy, in order to minimize postoperative risks. This technique has the advantage of being possibly performed at the bedside. It limits compression and lesions on the left lung and provides a direct view of PDA and vessels $(9,10)$.

Over the last couple of years, transcatheter PDA closure has emerged as a new alternative (11). Although not yet widely performed in preterm babies, several recent reports have described their efficacy and safety even in VLWB babies (12-14).

In this study, we aimed to assess the short- and mediumterm morbidity and mortality of surgical PDA ligation by anterior minithoracotomy, compared to transcatheter PDA closure, in preterm infants weighing $<1,600 \mathrm{~g}$.

\section{METHODS}

\section{Population}

We retrospectively analyzed data of two referring pediatric cardiology centers dealing with PDA closure in preterm babies. Patients originated from 13 different neonatal intensive care units (NICUs). The surgical group consisted of preterm infants who underwent anterior minithoracotomy ligation at center 1 (Marseille, France) between January 2010 and February 2020. The transcatheter group consisted of preterm infants who underwent percutaneous closure at center 2 (Paris, France) between January 2018 and February 2020. During these periods, there were no transcatheter PDA closures in center 1 (Marseille) and almost no surgical PDA closures in center 2 (Paris).

All preterm newborns with a hemodynamically significant PDA referred for PDA closure and weighing $<1,600 \mathrm{~g}$ were included. The indication of closure was entirely set by the neonatal teams, usually based on McNamara criteria (15) and after failure of or contraindication to medical treatment. In center 2, transcatheter closure was contraindicated if the anatomy or size of the PDA was not suitable for the insertion of the prosthesis, when the PDA was too short or too large and if adjacent structures were abnormal.

\section{Procedures}

The surgical technique (center 1) has been previously described (9). Most often, bedside ligation was proposed. The procedure was performed under general anesthesia, in supine position with a shoulder roll. A small $(1-1.5 \mathrm{~cm})$ horizontal parasternal skin incision was made in the third left intercostal space. After dissection of the intercostal muscle, pericardium was opened and suspended. PDA and left and right pulmonary arteries were exposed, and PDA clipped with one or two metallic vascular clips. Pericardium was closed, and pleural space was deaired.

For the percutaneous procedure, the patient was transferred from the original NICU to center 2 and transferred back at least $24 \mathrm{~h}$ after the catheterization, depending on clinical condition. ADO IIAS (Amplatzer ${ }^{\circledR}$, St Jude Medical copyright) devices were used. The Amplatzer Duct Occluder II Additional Sizes (now Piccolo) is contraindicated for infants $<700 \mathrm{~g}$ and before 3 days' postnatal age. As a rule of thumb, the diameter of the Piccolo device (3, 4, or $5 \mathrm{~mm}$ ) was chosen by adding $1 \mathrm{~mm}$ to the smallest diameter of the PDA, based on echocardiographic dimensions. The length of the PDA was not routinely measured. The shortest length of the Piccolo device $(2 \mathrm{~mm})$ was always chosen, to avoid left pulmonary artery or aortic obstruction. The procedure was performed under general anesthesia. Vascular access was obtained through the femoral vein. The procedure was echocardiography- and fluoroscopy-guided, limiting irradiation as much as possible. The technique evolved over time. In the earliest experience, systematic angiographies were performed for PDA measurement with limited amount of contrast. From October 2019, ductal measurements relied solely on echocardiographic assessment. As the center performing surgical closure was not offering transcatheter PDA closure, the patients in the surgical group were not evaluated for percutaneous closure.

\section{Outcomes}

The primary outcome was time to extubation after PDA closure.

We, in addition, investigated survival at discharge without procedural complication; severe morbidity, that is, grades 3-4 IVH (16); cystic PeriVentricular Leukomalacia stages II or III; NEC stage 3 or greater (17); ROP 3 and/or laser treatment (18); and severe BDP, defined as requiring oxygen for at least 28 days in addition to the requirement of $30 \%$ or more oxygen and/or mechanical ventilator support or continuous positive airway pressure at 36 weeks' postmenstrual age (19).

\section{Statistical Analyses}

Propensity score methodology was used to identify comparable transcatheter and surgical groups. Thirteen variables considered relevant were identified. Therefore, a propensity score was performed to match the transcatheter group patients with surgical group patients (1:1) according to gestational age, sex, weight, corrected age at intervention, associated heart defects, intrauterine growth restriction, NEC, NSAID 

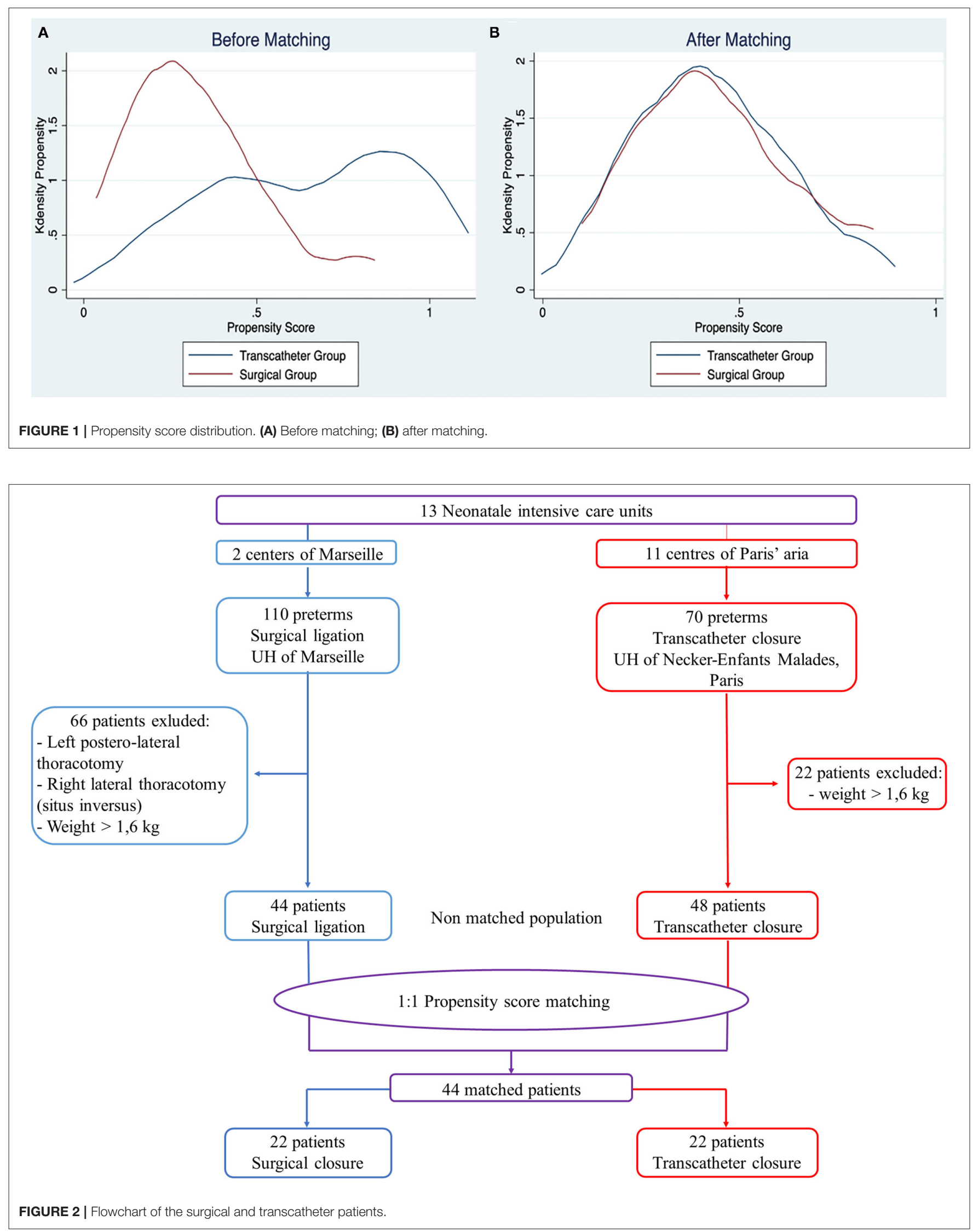
TABLE 1 | Patient characteristics before intervention.

\begin{tabular}{|c|c|c|c|c|c|c|}
\hline & \multicolumn{3}{|c|}{ Before matching } & \multicolumn{3}{|c|}{ After matching } \\
\hline & $\begin{array}{l}\text { Transcatheter } \\
(n=48)\end{array}$ & $\begin{array}{l}\text { Surgery } \\
(n=44)\end{array}$ & $p$-value & $\begin{array}{l}\text { Transcatheter } \\
\qquad(n=22)\end{array}$ & $\begin{array}{l}\text { Surgery } \\
(n=22)\end{array}$ & $p$-value \\
\hline Female, $n(\%)$ & $24(50)$ & $24(54.5)$ & 0.67 & $11(50)$ & $11(50)$ & 1 \\
\hline Gestational age, median (range min-max) (weeks) & $25.5(24-28)$ & $26(24-29)$ & 0.024 & $25.9(24-28)$ & $25.5(24-26.8)$ & 0.5 \\
\hline Birth weight, mean (SD) (g) & $751(119)$ & $756(143)$ & 0.89 & $754(126)$ & $798(116)$ & 0.22 \\
\hline Birth height, mean (SD) (cm) & $32.5(1.6)$ & $32.5(2.3)$ & 0.7 & $32.6(2)$ & $33.3(2)$ & 0.38 \\
\hline Antenatal corticosteroid, $n(\%)$ & $41(85.4)$ & $43(97.7)$ & 0.036 & $19(86.4)$ & $21(95.5)$ & 0.29 \\
\hline IUGR, $n(\%)$ & $3(6.2)$ & $17(38.6)$ & $<0.001$ & $3(13.6)$ & $1(4.5)$ & 0.29 \\
\hline Associated heart defects, $n(\%)$ & $10(20.8)$ & $14(31.8)$ & 0.23 & $5(22.7)$ & $5(22.7)$ & 1 \\
\hline PFO/IAC & $8(16.7)$ & $12(27.3)$ & & $5(22.7)$ & $5(22.7)$ & \\
\hline IVC & $1(2.1)$ & $1(2.3)$ & & $0(0)$ & $0(0)$ & \\
\hline PVS & $1(2.1)$ & $1(2.3)$ & & $0(0)$ & $0(0)$ & \\
\hline Hyaline membrane disease, $n(\%)$ & 47 (97.9) & $44(100)$ & 0.34 & $22(100)$ & $22(100)$ & \\
\hline IV duration, mean (SD) (d) & $21(12)$ & $18(10)$ & 0.24 & $21(12)$ & $18(12)$ & 0.66 \\
\hline NIV duration, mean (SD) (d) & $12(13)$ & $8(11)$ & 0.06 & $10(11)$ & $11(14)$ & 0.97 \\
\hline Need for HFO, $n(\%)$ & $34(70.8)$ & $36(81.8)$ & 0.22 & $17(77.3)$ & $16(72.7)$ & 0.73 \\
\hline Need for iNO, $n(\%)$ & $12(25)$ & $14(31.8)$ & 0.47 & $4(18.2)$ & $5(22.7)$ & 0.71 \\
\hline NEC, $n(\%)$ & 7 (14.6) & $5(11.4)$ & 0.65 & $2(9.1)$ & $1(4.5)$ & 0.56 \\
\hline Fetomaternal infection, $n(\%)$ & $20(41.7)$ & 35 (79.5) & $<0.001$ & $10(45.5)$ & $18(81.8)$ & 0.01 \\
\hline IVH (all grades), $n(\%)$ & 19 (39.6) & $10(22.7)$ & 0.08 & $8(36.4)$ & $6(27.3)$ & 0.52 \\
\hline \multicolumn{7}{|l|}{ PDA criteria } \\
\hline NSAIDs ( $\geq 1), n(\%)$ & $41(85.4)$ & 40 (90.9) & 0.42 & $19(86.4)$ & $21(95.5)$ & 0.29 \\
\hline DA size, mean (SD) (mm) (TTE) & $3.1(0.6)$ & $2.9(0.8)$ & 0.06 & $3.2(0.8)$ & $2.8(0.6)$ & 0.03 \\
\hline Corrected age at intervention (weeks) median (range min-max) & $30.5(26-34)$ & $30.4(26-43)$ & 0.94 & $30(27-33)$ & $29,7(27-38)$ & 0.4 \\
\hline CA at intervention, mean (SD) (weeks) & $30.5(1.6)$ & $30(1.7)$ & 0.08 & $30.4(1.5)$ & $30.1(1.6)$ & 0.31 \\
\hline Weight at intervention, mean (SD) (g) & $1,191(203)$ & $1,082(210)$ & 0.037 & $1,186(204)$ & $1,157(165)$ & 0.79 \\
\hline \multicolumn{7}{|l|}{ Ventilatory support at intervention, $n(\%)$} \\
\hline IV (CV or HFO) & $32(66.7)$ & $35(79.5)$ & 0.17 & $16(72.7)$ & $16(72.7)$ & 1 \\
\hline NIV (CPAP or HFNC) & $15(31.2)$ & $8(18.2)$ & 0.15 & $6(27.3)$ & $6(27.3)$ & 1 \\
\hline SNC & $1(2.1)$ & $1(2.1)$ & 0.95 & $0(0)$ & $0(0)$ & \\
\hline iNO & $4(8.3)$ & $2(4.5)$ & 0.46 & $1(4.5)$ & $1(4.5)$ & 1 \\
\hline $\mathrm{FiO}_{2}$ at intervention, mean (SD) (\%) & $41(21)$ & $30(10)$ & 0.002 & $42(19)$ & $28(9)$ & 0.001 \\
\hline Vasopressive drugs at intervention, $n(\%)$ & $1(2.1)$ & 9 (20.5) & 0.005 & $1(4.5)$ & $1(4.5)$ & 1 \\
\hline Creatinemia at intervention, mean (SD) ( $\mu \mathrm{mol} / \mathrm{L})$ & $48.6(30.4)$ & $57(23.9)$ & 0.005 & $54(38.1)$ & $51.5(14.4)$ & 0.24 \\
\hline Hemoglobin at intervention, mean (SD) (g/dL) & $11.7(1.5)$ & $10.3(1.9)$ & 0.001 & $11.9(1.7)$ & $9.9(1.8)$ & 0.004 \\
\hline Blood transfusion the day before intervention, $n(\%)$ & $18(40.9)$ & $21(47.7)$ & 0.52 & $7(36.8)$ & $11(50)$ & 0.4 \\
\hline
\end{tabular}

Data are presented as n (\%) unless stated differently.

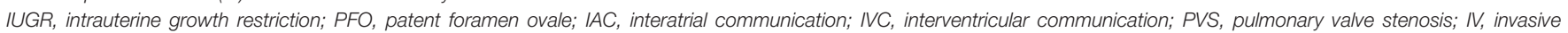

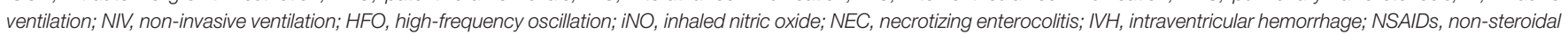

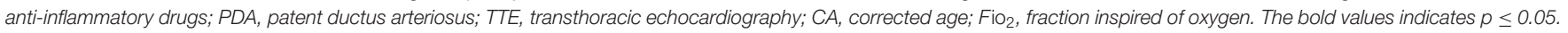

administration, high-frequency oscillation, invasive or noninvasive ventilation, vasopressive drugs administration, and creatinine level before intervention. Patients were matched using the nearest neighbor method without replacement and using a caliper width of 0.2 of the pooled standard deviation (SD) of the logit of the propensity score. This process yielded 22 well-matched pairs from the 44 surgical cases (50\% matched) (Figure 1).

Patients' data were expressed as mean \pm SD. Tests for normality were performed (Kolmogorov-Smirnov and ShapiroWilk). Only two variables (gestational age and corrected age at intervention) deviated from a normal distribution. There two variables were expressed as median, max, and min. Categorical data are summarized using frequencies and percentages; comparisons were made using the $\chi^{2}$ test or Fisher exact test when the number of values was $<5$. The results were compared, for paired data, using the McNemar test for categorical variables and the Wilcoxon paired signed rank test for quantitative variables. Statistical significance was established as $p<0.05$. Statistical analyses were performed using STATA statistics (StataCorp LP, College Station, TX). 


\section{Ethics Statement}

This study was approved by the local ethics committee (reference 2020-02-04-03).

\section{RESULTS}

\section{Population}

Before matching, 44 patients were included in the surgical group and 48 in the transcatheter group (Figure 2). These patients presented significant differences for 13 demographic variables, including age and weight at intervention (Table 1). After matching, two groups of 22 patients each were obtained.

TABLE 2 | Perioperative outcomes.

\begin{tabular}{lccc}
\hline & $\begin{array}{c}\text { Transcatheter } \\
(\boldsymbol{n}=\mathbf{2 2})\end{array}$ & $\begin{array}{c}\text { Surgery } \\
(\boldsymbol{n}=\mathbf{2 2})\end{array}$ & $\boldsymbol{p}$-value \\
\hline Time to extubation (day) & $9(13)$ & $10(15)$ & 0.88 \\
$\quad$ Total IV duration (day) & $28.5(21.4)$ & $29.9(22.5)$ & 0.68 \\
Postintervention NIV duration (day) & $21(15)$ & $21(19)$ & 0.96 \\
$\quad$ Total NIV duration (day) & $30(16.4)$ & $32.2(18.5)$ & 0.87 \\
Postintervention oxygenotherapy & $47(16)$ & $52(35)$ & 0.95 \\
duration (day) & & & \\
CA at weaning off oxygen (weeks) & $36.9(2.5)$ & $37.2(4.9)$ & 0.72 \\
Home leave with oxygen, $n$ (\%) & $6(28.6)$ & $4(21.1)$ & 0.58 \\
Death, $n$ (\%) & $1(4.5)$ & $2(9.1)$ & \\
Age at intensive care unit discharge (days) & $52(21)$ & $63(36)$ & 0.27 \\
Age at hospital discharge (days) & $105(19)$ & $114(29)$ & 0.24 \\
CA at hospital discharge (weeks) & $40.9(2.4)$ & $42.1(4)$ & 0.29 \\
Weight at hospital discharge (g) & $2,839(392)$ & $2,860(752)$ & 0.44 \\
\hline
\end{tabular}

Data are presented as mean $(S D)$ unless stated differently.

$I V$, invasive ventilation; NIV, non-invasive ventilation; $C A$, corrected age.

\section{Patient Characteristics Before Intervention}

Demographic data are shown in Table 1. Mean weeks and birth weight were $25.9 \pm 1.1$ weeks and $754 \pm 126 \mathrm{~g}$, respectively, in the transcatheter group and $25.8 \pm 1$ weeks $(p=0.54)$ and $798 \pm$ $116 \mathrm{~g}(p=0.22)$, respectively, in the surgical group.

At the time of the intervention, mean age, and weight were 31 \pm 11 days and $1,186 \pm 204 \mathrm{~g}$, respectively, in the transcatheter group and $30.4 \pm 1.5$ days $(p=0.5)$ and $1,157 \pm 165 \mathrm{~g}(p=0.79)$, respectively, in the surgical group.

Regarding radiation exposure in the transcatheter group, the median dose area product was $7.7 \pm 5.1 \mu \mathrm{Gy} / \mathrm{m}^{2}$.

\section{Outcomes}

Mean time to extubation was similar in both groups: $9 \pm 13$ days in the transcatheter group and $10 \pm 15$ days in the surgical group $(p=0.89)$ (Table 2, Figure 3).

All procedures succeeded except one in the transcatheter group, because of the creation of an aortic stenosis by the percutaneous device that had to be removed during the same procedure. Two residual shunts (9\%) were seen on postprocedure echocardiography the day after intervention in the transcatheter group but disappeared a few days later. No significant left pulmonary artery or aortic stenosis was seen in the two groups. Three complications occurred in 2 of 22 patients (9\%) in the transcatheter group: chylothorax $(n=1)$, endocarditis $(n=1)$, and renal vein thrombosis $(n=1)$. Five complications occurred in 3 of 22 patients (14\%) in the surgical group: pneumothorax $(n=2)$, chylothorax $(n=2)$, and phrenic nerve injury $(n=$ 1) $(p=0.63)$ (Table 3). Post-cardiac ligation syndrome (PCLS) occurred in 2 of 22 patients (9\%) of the surgical group vs. none in the transcatheter group $(p=0.14)$. After intervention, the mean creatinine level was similar between both groups $(p=0.61)$. One patient died in the transcatheter group and two in the surgical

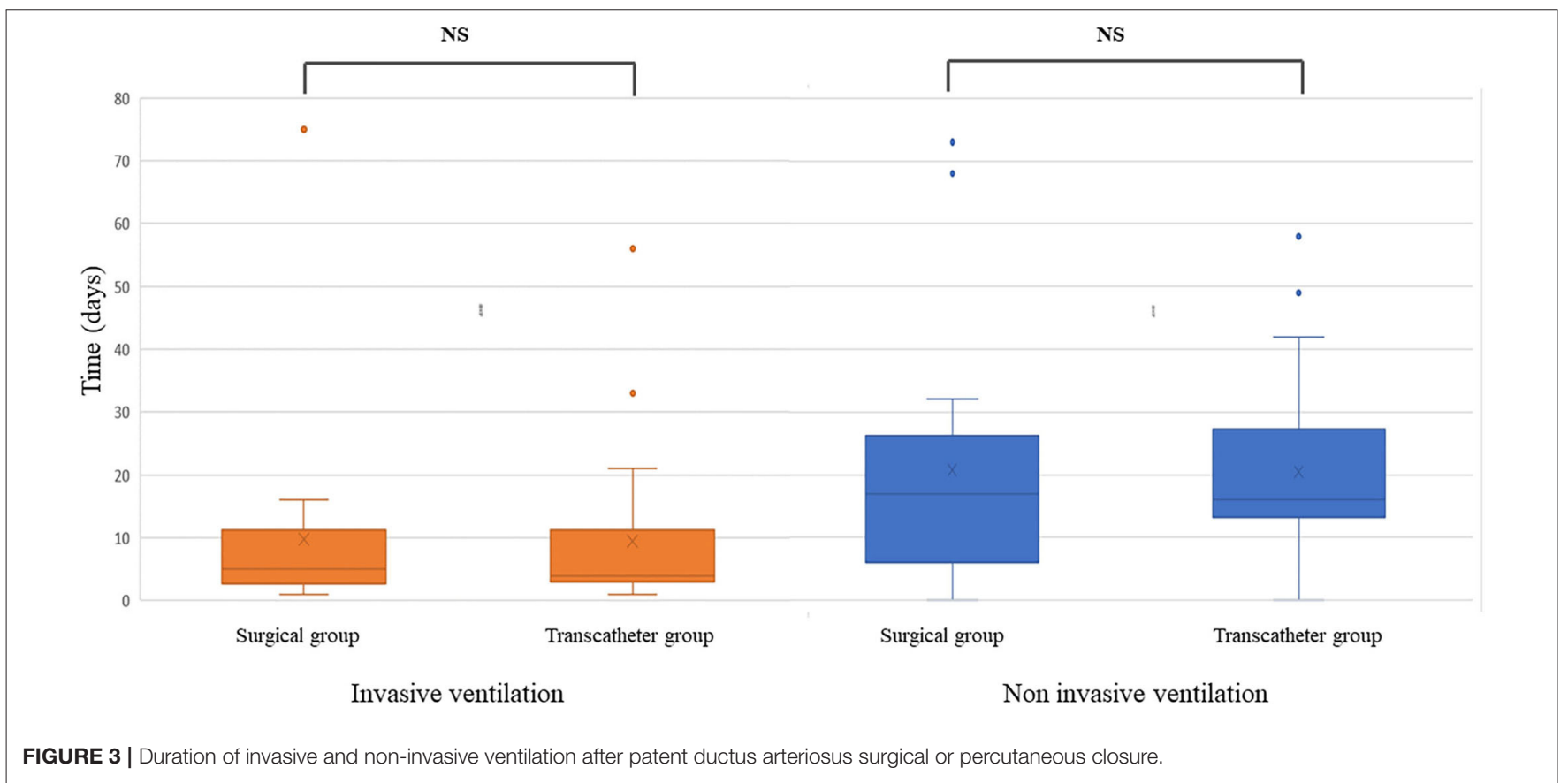


group. Two patients died because of sepsis not related to the intervention. One patient died of cardiac tamponade 10 days after surgery complicated by hemorrhage of the pulmonary trunk. Mean total invasive ventilation duration was $28.5 \pm 21.4$ days in the transcatheter group and $29.9 \pm 22.5$ days in the surgical group $(p=0.68)$, and mean total non-invasive ventilation duration was $31.1 \pm 17.3$ days $(p=0.87)$ in the two groups. Mean oxygen therapy length and oxygen treatment at discharge were similar between both groups $(p=0.96, p=0.58)$.

Half of the patients in each group had secondary sepsis unrelated to the procedure. IVH (any grade) was detected during follow-up in three patients (14\%) in the transcatheter group and in two patients $(9 \%)$ in the surgical group $(p=0.63)$.

Mean age at NICU discharge and mean age at hospital discharge were similar between both groups $(p=0.27, p=0.25)$.

\section{DISCUSSION}

Our study compares transcatheter vs. surgical (anterior minithoracotomy) PDA closure in very small preterm babies. To our knowledge, this is the first series comparing these two techniques.

The results of this study are encouraging whatever the technique used, but it is necessary to always consider the least invasive approach possible for these fragile infants (Figure 4), depending on the local skills and settings. We have to be careful not to expose these patients to unnecessary procedures. Indeed, according to Sankar et al. (3), in a recent literature review, early, routine, and widespread treatment to close the PDA in preterm infants does not lead to better outcomes. Some centers even tend toward an expectative approach and prefer to forego surgery after failure of drug treatment $(2,12)$. Mitra et al. describe a spontaneous closure rate of $\sim 75 \%$ at the end of the first year of life in premature infants born $<27$ weeks, discharged at home with a PDA (20). This debate is not to be resolved in this study, and there is a real cohort of patients who benefit from PDA closure (those born $<26$ weeks, with chronic respiratory insufficiency or clear signs of hemodynamic repercussions) (3, 21). The indication of PDA closure has to remain in the hands of the neonatologists in charge of the patient.

Surgical ligation through left thoracotomy, as initially described by Gross in 1938 (8), has potential complications, in particular the risks of PCLS (5, 22-24), pneumothorax, chylothorax, vocal cord paralysis, and infection $(25,26)$. In order to minimize these risks, a less invasive surgical approach can be used, derived from the technique by anterior mini-thoracotomy $(10,21)$. We believe that this technique is effective and safe for very low birth weight (VLBW) premature infants and limits the adverse effects, in particular due to a reduced operation time $(\sim 30 \mathrm{~min})$ and limited intraoperative compressions and lesions of the left lung. However, scientific data are scarce. Karaci et al. (10) reported similar results to ours: in 32 premature infants treated by anterior minithoracotomy with a mean weight of $823 \pm 25 \mathrm{~g}$, the mean time to extubation was $13.8 \pm$ 2.3 days.

Transcatheter PDA closure is now possible in VLBW preterm infants, thanks to the modification of the technique avoiding
TABLE 3 | Operative and postoperative outcomes.

\begin{tabular}{|c|c|c|c|}
\hline & $\begin{array}{l}\text { Transcatheter } \\
\qquad(n=22)\end{array}$ & $\begin{array}{l}\text { Surgery } \\
(n=22)\end{array}$ & $p$-value \\
\hline Procedural failure & $1(4.5)$ & $0(0)$ & 0.31 \\
\hline Per procedural complication & $0(0)$ & $2(9.1)$ & 0.14 \\
\hline $\mathrm{PAH}$ & $0(0)$ & $1(4.5)$ & \\
\hline Hemodynamic failure & $0(0)$ & $0(0)$ & \\
\hline Hemorrhage & $0(0)$ & $1(4.5)$ & \\
\hline $\begin{array}{l}\text { Patients with postprocedural } \\
\text { local complications }\end{array}$ & $2(9.1)$ & 3 (13.6) & 0.63 \\
\hline \multicolumn{4}{|l|}{ Complications detail: } \\
\hline PNO & 0 & 2 & \\
\hline Chylothorax & 1 & 2 & \\
\hline Diaphragmatic paralysis & 0 & 1 & \\
\hline Infectious endocarditis & 1 & 0 & \\
\hline Renal vein thrombosis & 1 & 0 & \\
\hline $\begin{array}{l}\text { Patients with postprocedural } \\
\text { general outcomes }\end{array}$ & $4(22)$ & $2(9)$ & 0.37 \\
\hline \multicolumn{4}{|l|}{ Outcomes details } \\
\hline $\mathrm{PAH}$ & $4(22)$ & $2(9)$ & 0.37 \\
\hline Hemodynamic failure & $0(0)$ & $2(9)$ & 0.14 \\
\hline Postligation cardiac syndrome & $0(0)$ & $2(9)$ & 0.14 \\
\hline Postintervention vasopressor drugs & $1(4.5)$ & $10(45)$ & 0.002 \\
\hline \multicolumn{4}{|l|}{ Postintervention TTE } \\
\hline Residual shunt at the first TTE & $2(9.1)$ & $0(0)$ & 0.14 \\
\hline Residual shunt $48 \mathrm{~h}$ after intervention & $0(0)$ & $0(0)$ & \\
\hline Coarctation of aorta & $0(0)$ & $0(0)$ & \\
\hline Moderate LPA stenosis & $1(4.5)$ & $0(0)$ & 0.31 \\
\hline Hemoglobin, mean (SD) (g/dL) & $11(1)$ & $12(2)$ & 0.85 \\
\hline
\end{tabular}

PAH, Pulmonary Arterial Hypertension; PNO, Pneumothorax ; LPA, Left Pulmonary Artery ; RPA, Right Pulmonary artery; TTE, transthoracic echocardiogram; PNO, Pneumothorax ; LPA, Left Pulmonary Artery.

Data are presented as $n(\%)$ unless stated differently. The bold values indicates $p \leq 0.05$

arterial access and thanks to miniaturization of the delivery system and new devices. This procedure remains technically challenging, and although its use is expanding, it remains limited to large and experienced centers (27).

Studies comparing transcatheter to conventional left thoracotomy surgery have shown the non-inferiority of this technique in terms of efficiency and morbidity-mortality $(25,28)$ and a faster respiratory improvement after procedure $(12,29)$.

In our study, time to extubation, respiratory outcome with rate of BPD at day 28 and 36 weeks, survival before discharge and morbidity were equivalent in the two groups and similar to those described in other studies $(14,30)$. Mortality and morbidity, however, were not negligible, probably related to the severity and fragility of the patients included in this study.

Although those two techniques seem to be comparable, they both have their advantages and limitations. Indeed, the main advantage of anterior minithoracotomy technique is that it can be performed at bedside without transfer, but there seemed to be more complications such as pleural lesions and PCLS, although the difference was not significant. PCLS is a classic complication 


\section{Anterior mini-thoracotomy versus transcatheter closure of patent ductus arteriosus in very preterm infants}

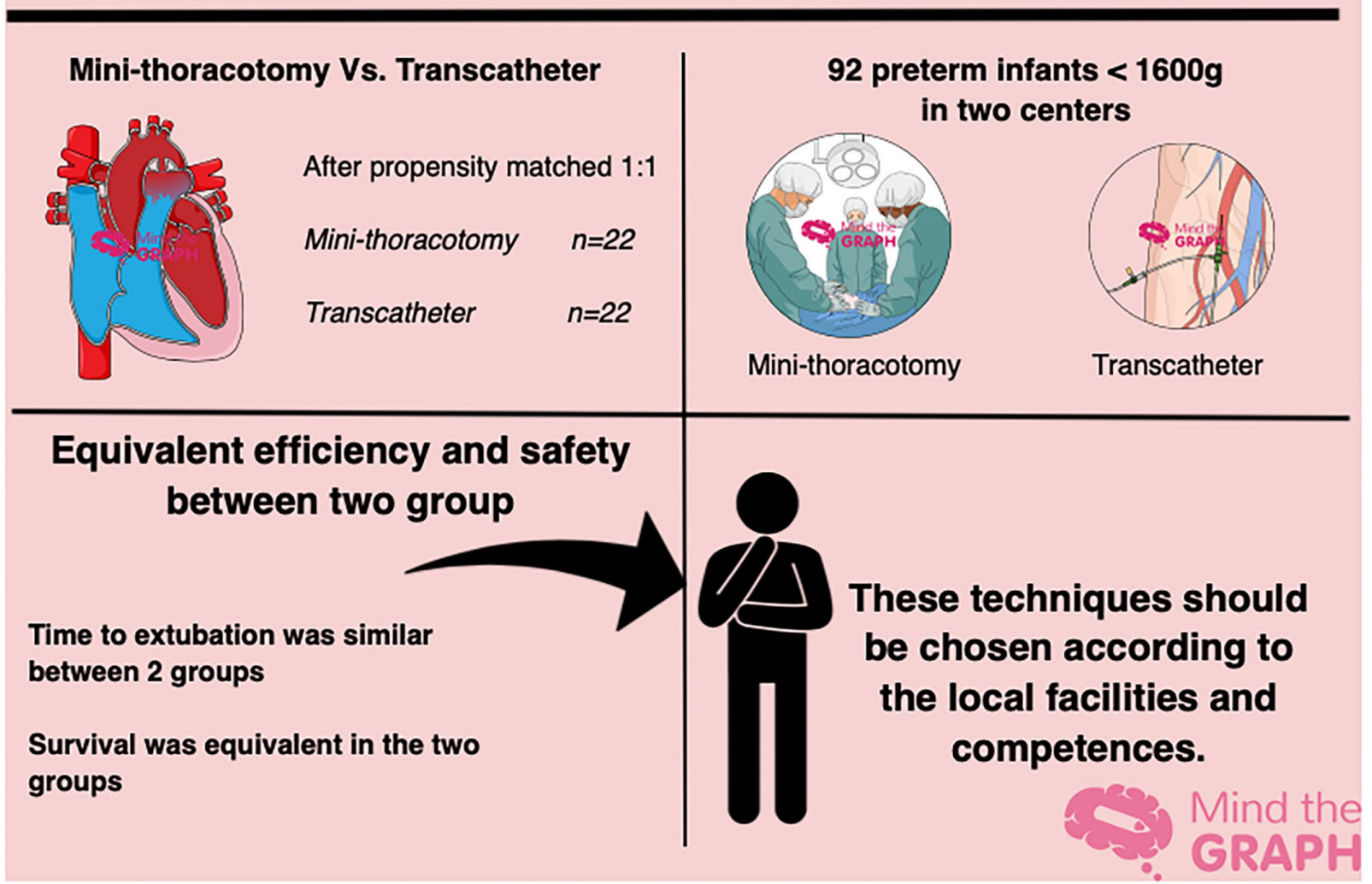

FIGURE 4 | Graphical abstract showing minithoracotomy vs. transcatheter in preterm infants $<1,600$ g with significant hemodynamic patent ductus arteriosus.

after PDA conventional surgical ligation. Its incidence is variable, ranging from 10 to $45 \%$, and is conversely proportional to gestational age and age and weight at surgery $(5,23,31)$. It has not been described after transcatheter PDA closure $(4,14,28)$. Furthermore, the need of vasopressive drugs after surgery was more important than after catheterization, consistent with the literature (21).

Percutaneous techniques present a risk, although low, of closure failure and require irradiation of the patient, reduced to a minimum, which averaged $7.7 \pm 5.1 \mu \mathrm{Gy} / \mathrm{m}^{2}$ in our population. Since October 2019, all percutaneous closures were done without angiography. Transthoracic echocardiogram plays indeed a key role in transcatheter PDA closure in preterm infants. With increasing experience of the sonographer, the morphology and dimensions of the ductus, the adequate placement of the device, the presence of residual shunting, and the absence of aortic or left PA obstruction are better appreciated by ultrasound (two-dimensional imaging and Doppler) than by angiography. Piatek et al. (32) described a case of contrastinduced hypothyroidism after percutaneous PDA device closure in VLBW preterm infants. This is one more reason to avoid angiography. In our study, one percutaneous closure failed, because the device caused an aortic coarctation and had to be removed. The PDA was nevertheless closed on the follow-up echocardiography the next day. Other potential complications may occur such as pulmonary artery stenosis, device embolization, and tricuspid regurgitation $(5,13,30)$ but were not observed in our matched population. In our study, patients did not have systematic echo Doppler of vascular access after procedure, so that the rate of vascular thrombosis could not be assessed.

\section{Limitations}

The major limitations to our study are the retrospective observational analysis and the presence of a bicentric cohort with each of the centers using only one technique. The management of preintervention and postintervention may have been different in the 13 NICUs in charge of the patients, in particular with regard to extubation criteria. We used a propensity score matching to minimize differences in characteristics before PDA closure. This resulted in a relatively small sample size, which may influence the power of some analyses and increase 
the risk of type II statistical error. In addition, despite matching, we were not able to capture all criteria related to prematurity, those specific to the practitioner, and to the procedure that may have played a role in preinterventional and peri-interventional care and influenced clinical outcomes. Evolution in preintervention and postintervention care over time needs to be considered, as well as the effects of the learning curve.

In addition, the period for inclusion of anterior minithoracotomy-treated infants spans 10 years, making it likely that other treatments and routines have changed during this time.

Further analyses are needed to study the long-term evolution of these premature newborns and to determine the impact on cardiac function and especially the size of pulmonary arteries and descending aorta.

In conclusion, mini-anterior thoracotomy PDA ligation and percutaneous PDA closure are two equivalent techniques that are effective, safe, and reproducible for preterm infants $<1,600 \mathrm{~g}$ with significant hemodynamic PDA. Local setting and facilities as well as technical expertise should drive choice of one vs. the other.

\section{REFERENCES}

1. Conrad C, Newberry D. Understanding the pathophysiology, implications, and treatment options of patent ductus arteriosus in the neonatal population. Adv Neonatal Care. (2019) 19:179-87. doi: 10.1097/ANC.0000000000000590

2. Benitz WE. Treatment of persistent patent ductus arteriosus in preterm infants: time to accept the null hypothesis? J Perinatol. (2010) 30:241-52. doi: $10.1038 /$ jp. 2010.3

3. Sankar MN, Bhombal S, Benitz WE. PDA: to treat or not to treat. Congenit Heart Dis. (2019) 14:46-51. doi: 10.1111/chd.12708

4. Sathanandam S, Agrawal H, Chilakala S, Johnson J, Allen K, Knott-Craig $\mathrm{C}$, et al. Can transcatheter PDA closure be performed in neonates $\leq 1000$ grams? The Memphis experience. Congenit Heart Dis. (2019) 14:79-84. doi: $10.1111 /$ chd. 12700

5. Ulrich TJB, Hansen TP, Reid KJ, Bingler MA, Olsen SL. Post-ligation cardiac syndrome is associated with increased morbidity in preterm infants. J Perinatol. (2018) 38:537-42. doi: 10.1038/s41372-018-0056-4

6. Mitra S, Rønnestad A, Holmstrøm H. Management of patent ductus arteriosus in preterm infants-where do we stand?: management of PDA in preterm infants. Congenit Heart Dis. (2013) 8:500-12. doi: 10.1111/chd.12143

7. Kim HS, Schechter MA, Manning PB, Eghtesady P, Balzer DT, Shahanavaz $S$, et al. Surgical versus percutaneous closure of PDA in preterm infants: procedural charges and outcomes. J Surg Res. (2019) 243:41-6. doi: 10.1016/j.jss.2019.04.069

8. Gross RE, Hubbard JP. Surgical ligation of patent ductus arteriosus, report of first successful case. JAMA. Mar. (1984) 251:1201-2. doi: 10.1001/jama.1984.03340330059026

9. Fouilloux V, Gran C, Kreitmann B. Surgical closure of persistent arterial duct with minimal invasive anterior thoracotomy: an alternative technique. Eur J Pediatr Surg. (2013) 24:431-2. doi: 10.1055/s-0033-1357752

10. Karaci AR, Sasmazel A, Turkay S, Aydemir N, Bugra H, Erdem H, et al. Closure of a patent ductus arteriosus in pre-term neonates using a left anterior mini-thoracotomy. J Card Surg. (2013) 28:461-4. doi: 10.1111/jocs.12135

11. Almeida-Jones M, Tang NY, Reddy A, Zahn E. Overview of transcatheter patent ductus arteriosus closure in preterm infants. Congenit Heart Dis. (2019) 14:60-4. doi: 10.1111/chd.12712

12. Sathanandam S, Balduf K, Chilakala S, Washington K, Allen K, KnottCraig C, et al. Role of transcatheter patent ductus arteriosus closure in

\section{DATA AVAILABILITY STATEMENT}

The raw data supporting the conclusions of this article will be made available by the authors, without undue reservation.

\section{ETHICS STATEMENT}

The studies involving human participants were reviewed and approved by (Committee Ethics of Aix-Marseille University) (reference 2020-02-04-03). Written informed consent to participate in this study was provided by the participants' legal guardian/next of kin.

\section{AUTHOR CONTRIBUTIONS}

All authors listed have made a substantial, direct, and intellectual contribution to the work and approved it for publication.

\section{ACKNOWLEDGMENTS}

We are grateful for the cooperation of neonatal units and pediatric cardiology centers participating in the study.

extremely low birth weight infants. Catheter Cardiovasc Interv. (2019) 93:8996. doi: $10.1002 / \mathrm{ccd} .27808$

13. Narin N, Pamukcu O, Baykan A, Sunkak S, Ulgey A, Uzum K. Percutaneous PDA closure in extremely low birth weight babies. J Intervent Cardiol. (2016) 29:654-60. doi: 10.1111/joic.12352

14. Zahn EM, Peck D, Phillips A, Nevin P, Basaker K, Simmons C, et al. Transcatheter closure of patent ductus arteriosus in extremely premature newborns. JACC Cardiovasc Interv. (2016) 9:2429-37. doi: 10.1016/j.jcin.2016.09.019

15. McNamara PJ, Sehgal A. Towards rational management of the patent ductus arteriosus: the need for disease staging. Arch Dis Child Fetal Neonatal Ed. (2007) 92:F424-7. doi: 10.1136/adc.2007.118117

16. Papile L-A, Burstein J, Burstein R, Koffler H. Incidence and evolution of subependymal and intraventricular hemorrhage: a study of infants with birth weights less than 1,500 gm. J Pediatr. (1978) 92:529-34. doi: 10.1016/S0022-3476(78)80282-0

17. Bell MJ, Ternberg JL, Feigin RD, Keating JP, Marshall R, Barton L, et al. Neonatal necrotizing enterocolitis. Ann Surg. Jan. (1978) 187:1-7. doi: 10.1097/00000658-197801000-00001

18. International Committee for the Classification of Retinopathy of Prematurity. The international classification of retinopathy of prematurity revisited. Arch Ophthalmol. (2005) 123:991-9. doi: 10.1001/archopht.123.7.991

19. Jobe AH. The new bronchopulmonary dysplasia. Curr Opin Pediatr. (2011) 23:167-72. doi: 10.1097/MOP.0b013e3283423e6b

20. Mitra S, Florez ID, Tamayo ME, Aune D, Mbuagbaw L, Veroniki AA, et al. Effectiveness and safety of treatments used for the management of patent ductus arteriosus (PDA) in preterm infants: a protocol for a systematic review and network meta-analysis. BMJ Open. (2016) 6:e011271. doi: 10.1136/bmjopen-2016-011271

21. Abu Hazeem AA, Gillespie MJ, Thun H, Munson D, Schwartz MC, Dori Y, et al. Percutaneous closure of patent ductus arteriosus in small infants with significant lung disease may offer faster recovery of respiratory function when compared to surgical ligation: percutaneous closure of PDA in small infants. Catheter Cardiovasc Interv. (2013) 82:526-33. doi: 10.1002/ccd.25032

22. McNamara PJ, Stewart L, Shivananda SP, Stephens D, Sehgal A. Patent ductus arteriosus ligation is associated with impaired left ventricular systolic performance in premature infants weighing less than $1000 \mathrm{~g}$. J Thorac Cardiovasc Surg. (2010) 140:150-7. doi: 10.1016/j.jtcvs.2010.01.011 
23. Noori S, Kumar SR. Pre-dicting post-ligation syndrome. J Thorac Cardiovasc Surg. (2017) 154:2060-1. doi: 10.1016/j.jtcvs.2017.08.048

24. Moin F, Kennedy KA, Moya FR. Risk factors predicting vasopressor use after patent ductus arteriosus ligation. Am J Perinatol. (2003) 20:313-20. doi: $10.1055 /$ s-2003-42693

25. Jhaveri N, Moon-Grady A, Clyman RI. Early surgical ligation versus a conservative approach for management of patent ductus arteriosus that fails to close after indomethacin treatment. J Pediatr. (2010) 157:381-7.e1. doi: 10.1016/j.jpeds.2010.02.062

26. Engeseth MS, Olsen NR, Maeland S, Halvorsen T, Goode A, Røksund OD. Left vocal cord paralysis after patent ductus arteriosus ligation: a systematic review. Paediatr Respir Rev. (2018) 27:74-85. doi: 10.1016/j.prrv.2017.11.001

27. Rodríguez Ogando A, Planelles Asensio I, de la Blanca ARS, Ballesteros Tejerizo F, Sánchez Luna M, Gil Jaurena JM, et al. Surgical ligation versus percutaneous closure of patent ductus arteriosus in very low-weight preterm infants: which are the real benefits of the percutaneous approach? Pediatr Cardiol. (2018) 39:398-410. doi: 10.1007/s00246-017-1768-5

28. Vali P, Lakshminrusimha S, Pelech A, Underwood M, Ing F. Patent ductus arteriosus in preterm infants: is early transcatheter closure a paradigm shift? $J$ Perinatol. (2019) 39:1449-61. doi: 10.1038/s41372-019-0506-7

29. Baruteau A-E, Regan W, Benbrik N, Sharma S, Auriau J, Romefort B, et al. Improved ventilation and hospital stay in premature babies after transcatheter closure of patent ductus arteriosus as compared to surgical ligation: a multi-center comparative study. Arch Cardiovasc Dis Suppl. (2019) 11:e380. doi: 10.1016/j.acvdsp.2019.06.003

30. Mashally S, Nield LE, McNamara PJ, Martins FF, El-Khuffash A, Jain A, et al. Late oral acetaminophen versus immediate surgical ligation in preterm infants with persistent large patent ductus arteriosus. J Thorac Cardiovasc Surg. (2018) 156:1937-44. doi: 10.1016/j.jtcvs.2018.05.098
31. Teixeira LS, Shivananda SP, Stephens D, Van Arsdell G, McNamara PJ Postoperative cardiorespiratory instability following ligation of the preterm ductus arteriosus is related to early need for intervention. J Perinatol. (2008) 28:803-10. doi: 10.1038/jp.2008.101

32. Piatek M, Schneider DJ, Smith WJ, Hanna M, Abu Jawdeh EG. Hypothyroidism after percutaneous patent ductus arteriosus device closure in an Extremely Preterm Infant: possible role of iodinated IV contrast. Neonatology. (2020) 117:776-9. doi: 10.1159/000 512110

Conflict of Interest: The authors declare that the research was conducted in the absence of any commercial or financial relationships that could be construed as a potential conflict of interest.

Publisher's Note: All claims expressed in this article are solely those of the authors and do not necessarily represent those of their affiliated organizations, or those of the publisher, the editors and the reviewers. Any product that may be evaluated in this article, or claim that may be made by its manufacturer, is not guaranteed or endorsed by the publisher.

Copyright (C) 2021 Lenoir, Wanert, Bonnet, Méot, Tosello, Fouilloux, Ovaert and Malekzadeh-Milani. This is an open-access article distributed under the terms of the Creative Commons Attribution License (CC BY). The use, distribution or reproduction in other forums is permitted, provided the original author(s) and the copyright owner(s) are credited and that the original publication in this journal is cited, in accordance with accepted academic practice. No use, distribution or reproduction is permitted which does not comply with these terms. 